\title{
Estimating the potential annual welfare impact of innovative drugs in use in Switzerland
}

\author{
Matea Pavic ${ }^{1 *}$, Alena M. Pfeil ${ }^{2}$ and Thomas D. Szucs ${ }^{2}$ \\ ${ }^{1}$ University of Zurich, Zurich, Switzerland \\ ${ }^{2}$ Institute of Pharmaceutical Medicine (ECPM), University of Basel, Basel, Switzerland
}

Edited by:

Dihua Xu, National Institute of Health, USA

\section{Reviewed by:}

Aijun Ye, Eunice Kennedy Shriver National Institute of Child Health and Human Development, USA

Jia Liu, Pfizer Inc., USA

\section{*Correspondence:}

Matea Pavic, University of Zurich, St. Niklausstr. 15, Unterengstringen, Zurich 8103, Switzerland e-mail:m.pavic@gmx.net
Expenditures of health care systems are increasing from year to year. Therefore, this study aimed to estimate the difference in costs and benefits of innovative pharmaceuticals launched 2000 onward compared to standard treatment on the national economy of Switzerland in 2010. The approach and formula described in the pilot study by Tsiachristas et al. (1), which analyzed the situation of welfare effects in the Netherlands, served as a model for our own calculations. A literature search was performed to identify costutility or cost-effectiveness studies of drugs launched 2000 onward compared to standard treatment. All parameters required for the calculation of welfare effects were derived from these analyses. The base-case threshold value of a quality-adjusted life year was set to CHF 100,000. Overall, 31 drugs were included in the welfare calculations. The introduction of innovative pharmaceuticals since 2000 onward to the Swiss market led to a potential welfare gain of about CHF 781 million in the year 2010. Univariate sensitivity analysis showed that results were robust. Probably because of the higher benefits of new drugs on health and quality of life compared to standard treatment, these drugs are worth the higher costs. The literature search revealed that there is a lack of information about the effects of innovative pharmaceuticals on the overall economy of Switzerland. Our study showed that potential welfare gains in 2010 by introducing innovative pharmaceuticals to the Swiss market were substantial. Considering costs and benefits of new drugs is important.

Keywords: welfare impact, cost-effectiveness, innovative drugs, economic evaluation, quality-adjusted life year

\section{INTRODUCTION}

The expenditures of most health care systems, e.g., the US and several European health care systems (2) increased from year to year, the same is true for the Swiss health care system (3). Hence, there is an ongoing debate on how to stop or reduce the increase in health care expenditures and keep the costs on an affordable level. Compared to other countries, such as the US, Germany, France, Austria, etc., Switzerland spent less on drugs in 2010 (Figure 1) (4). Although pharmaceutical expenditure in 2010 only accounted for $9.7 \%$ (CHF 6.05 billion) of total health care expenditure in Switzerland (CHF 62.5 billion in 2010) (Figure 2) and even decreased compared to the year 2009 (CHF 6.18 billion or $10.1 \%$ of total health care expenditure) (5), health policy and health decision-makers focused mainly on the price of novel and existing medicines.

New or innovative medicines are often more expensive than well-established drugs. This supports the common opinion that the expenditures on drugs are too high and should be reduced. For this reason, politicians and decision-makers often focus on the price of a new drug when there are negotiations about introducing a new drug to the Swiss market. Seldom is attention paid to the fact that a new drug may have additional effects on the health state or the quality of life of a patient compared to the standard drug, i.e., the currently most prescribed drug for a given indication. For example, the new drug costs more than the standard therapy. Without considering additional costs or benefits, we would conclude that medical treatment of the patient with the new drug is more expensive than treating the patient with the standard drug. Suppose that the new drug reduces hospital length of stay or number of physician visits compared to the standard therapy (6). This could result in reduced resource use by the patient, which could save costs in patients' care (7). These additional benefits including externalities may outweigh the drug expenditures, and in the end we may generate welfare gains due to the prescription of new drugs. There is also evidence in international literature that health care expenditure positively effects on outcomes $(8,9)$ and increase in drug spending leads to cost savings in other health care expenditures and these savings often outweigh the spending (10-12). Others argument that over the past 50 years, the majority of new products (up to $90 \%$ ) have provided only few benefits, but also considerable harms that have added to national healthcare costs (13).

The timeliness of this topic is supported by a ruling of the Swiss Federal Court of Justice in 2010 which stated that the treatment of Morbus Pompe, which is a very rare disease, at CHF 500,000 per year is too expensive given its only small health effects and that health insurers are not required or forced to pay for such treatments beyond the proposed threshold of CHF 100,000/QALY (14, 15). This is the first time that a formal and in this case legally binding cost-effectiveness threshold has been suggested in Switzerland.

To evaluate the health economic impact of a new pharmaceutical, it is required to conduct a cost-effectiveness analysis that considers not only the additional costs a new drug has compared to an alternative, but also the additional benefits. Ideally, the result of the cost-effectiveness analysis is presented as the ratio 

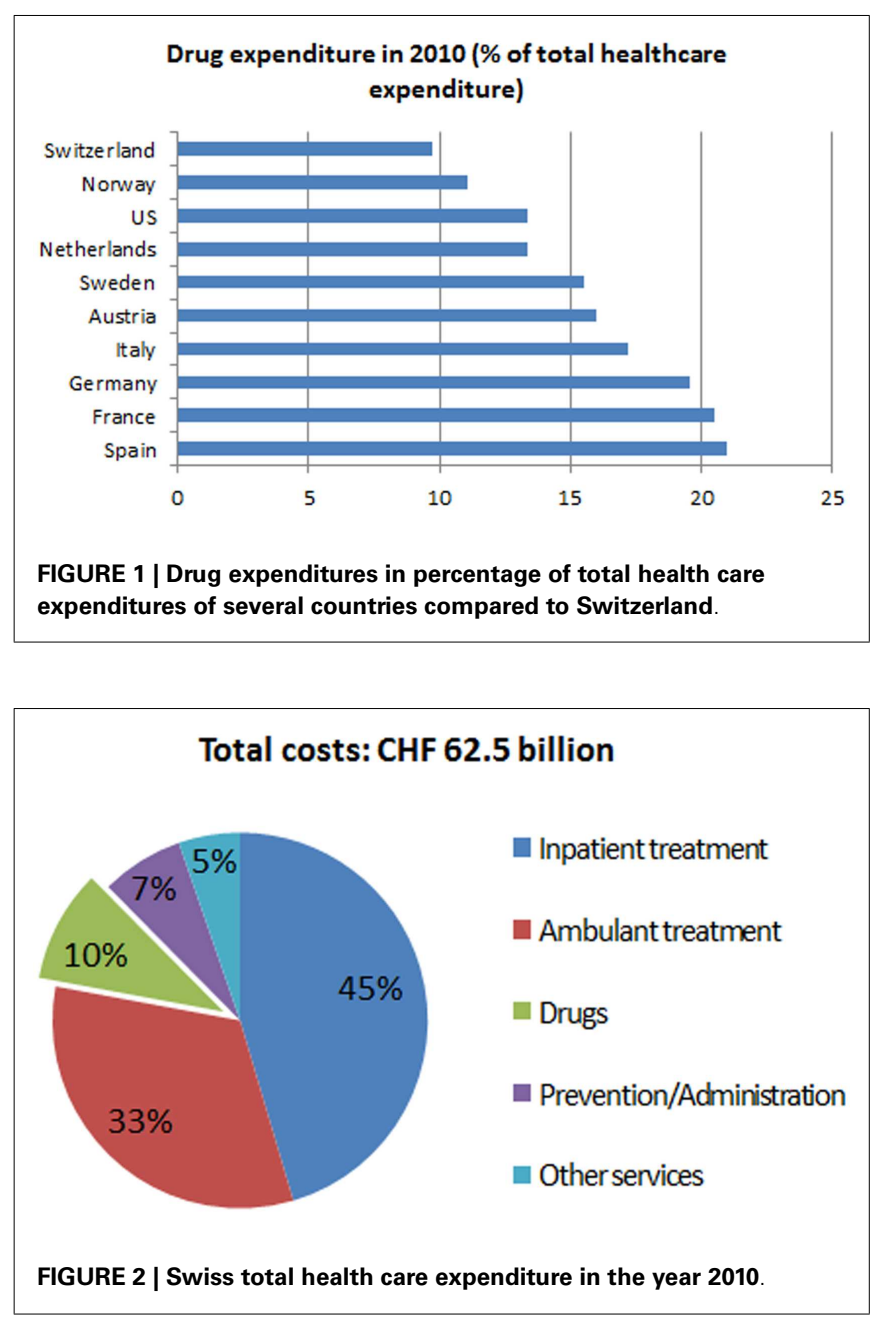

of the differences of costs and QALYs (incremental cost-utility ratio, ICUR) for the new drug compared to standard treatment, because ICURs are not indication-specific and therefore, ICURs of different diseases can be compared to each other.

The aim of this analysis was to show the importance of considering the costs of a new drug as well as its benefits from a Swiss perspective and to evaluate the total potential annual welfare impact due to the implementation of new drugs for the Swiss economy in 2010 .

\section{MATERIALS AND METHODS}

To the best of our knowledge, we are the first to assess the welfare effects of innovative drugs in Switzerland. Another such evaluation has already been performed in the Netherlands, which revealed great potential welfare gains of introducing new pharmaceuticals to the market (1). This evaluation and published report by Tsiachristas et al. (1) provided the methodological basis for our own calculations. The aim of the exploratory study was to establish knowledge in the welfare impact of innovative drugs introduced to the Dutch market after 1997 to reflect a 10-year time horizon. The authors mainly used pharmacoeconomic studies collected by the Dutch Health Care Insurance Board (CVZ), the British National
Institute for Health and Clinical Excellence (NICE), and the Canadian Agency for Drugs and Technologies in Health (CADTH). A limited number of studies have been also collected from the scientific literature and in total, 52 studies were included. The heterogeneous and foreign studies have been roughly adjusted to the Dutch situation by using purchasing power parities (PPP) and the deflator of the gross domestic product (GDP) as it is difficult to adjust for varying cost calculation methods and other countryspecific aspects of a pharmacoeconomic evaluation. The welfare gains amounted to $€ 1.7$ billion based on a QALY valuation of $€ 50,000$. Further details of the methodology have already been extensively described in the report (1).

Our approach was to estimate the welfare impact of a basket of novel and innovative drugs in Switzerland for the year 2010, which were launched 2000 onward. The parameters needed for these calculations were derived from published literature.

\section{LITERATURE SEARCH}

A restrictive literature search based on the results of Tsiachristas et al. (1) was conducted using the databases PubMed, the Cost-Effectiveness Analyses (CEA) Registry, and data from the Centre for Review and Dissemination (CRD). The search focused on cost-effectiveness and cost-utility analyses, respectively. References from the beginning of the study up to 31st October 2010 were included. The included studies were restricted to English and German language. The search focused on publications reporting CEA of new drugs launched 2000 onward in Switzerland. Titles, abstracts, and finally full-texts of the articles found within the search were screened to assess the eligibility of those costeffectiveness, respectively, cost-utility analyses. Studies that fulfilled the following pre-defined inclusion criteria were considered:

- Costs were reported transparently and the reference price year was presented

- The outcome measure was expressed in QALYs (preferred outcome measure) or life years gained (LYG)

- At least, an incremental cost-effectiveness ratio (ICER, additional costs per additional effects, e.g., LYG, blood pressure reduced by one unit, etc.) was reported (an ICUR was preferred)

- the time horizon was clearly stated.

For our analysis, it would have been more accurate to consider only studies from a societal perspective (16). The societal perspective includes not only the direct cost such as drug costs, hospitalization costs, or costs for a physician visit, but also considers the indirect cost, e.g., the costs of productivity losses, work absences, or informal care by family members. The literature search identified only few studies from a societal perspective that met the inclusion criteria. Hence, several studies from a health care payer perspective had to be included in our analysis as well.

\section{CALCULATING THE WELFARE IMPACT}

The cost-effectiveness of a drug is not only influenced by its costs and effects, but also by the society's willingness-to-pay (WTP) for a QALY or by the determined cost-effectiveness threshold of a country. The cost-effectiveness threshold commonly used in the US varies between US\$ 50,000 and US\$ 100,000 per QALY 
(17). NICE acceptable cost-effectiveness thresholds for the UK are set at $\mathfrak{E} 20,000-30,000$ per QALY (18). There is no official costeffectiveness threshold in Switzerland, but as mentioned above, there was recently a discussion on this health topic initiated by a ruling of the Federal Court of Justice in 2010 that one life year saved is worth about CHF 100,000 $(14,15)$. Accordingly, we assumed that in Switzerland the commonly used and accepted cost-effectiveness threshold is CHF 100,000/QALY. However, in Switzerland this threshold is still arguable and there will be further discussions on this in the future.

To calculate the potential welfare impact of a new drug, it is required to know the ICER, respectively, ICUR of this drug compared to the standard treatment. Whereas the ICER is the ratio between the additional costs of a drug compared to an alternative treatment and the additional effects gained, respectively, effects lost with the drug compared to an alternative ( $\Delta$ costs/ $\Delta$ effects), the ICUR is the ratio between the additional costs of a drug compared to an alternative treatment and the additional QALYs gained, respectively, QALYs lost ( $\Delta$ costs/ $\triangle$ QALYs). One possibility to get the ICERs/ICURs of innovative drugs would have been to perform several CEA of the respective drugs on our own, but as these analyses have to be performed comprehensively and are therefore very time-consuming, we decided to derive the ICERs/ICURs from already published cost-effectiveness studies of the respective drugs.

The more patients benefit from a drug, the more attractive is it not only from a healthcare point of view but also economically. Hence, the number of patients possibly benefiting from the drug was needed to calculate the welfare impact. The potential number of users includes all patients who could possibly be treated with a drug, but that is not always the same as actual users as not all people affected by a disease get treated. Therefore, the best way to assess the potential number of users is the estimated number of customers from the manufacturer. Because the number of all patients potentially benefiting of the respective drug was difficult to obtain, the actual number of users had to be used in most cases. Only for four different drugs, namely conjugated vaccine, ibandronate, atorvastatin, and memantine, the information about the potential number of users was directly provided from the manufacturer. For risperdal and mimpara, the number of drug packages sold in 2010 was provided by the pharmaceutical manufacturer (IMS Health sales figures) and the number of actual users was calculated indirectly based on the usual dosage prescribed (19). For the other drugs, the number of actual users was provided by the largest health insurance group in Switzerland, Helsana. These numbers were not presented in the results due to confidentiality reasons. The benefit from a drug also depends on the duration of the effect, in this case approximately the time horizon (which was either 1 year, as long as the duration of the treatment or longer) used in the cost-effectiveness models, which was also retrieved from the published literature.

Finally, the potential Swiss welfare impact in 2010 of a new drug was calculated by using the following equation developed by Tsiachristas et al. (1):

$$
\begin{aligned}
& \text { Welfare impact }=\left[\mathrm{QALY}_{\text {value }}-\text { cost/QALY }\right] \\
& \quad \times[\Delta \mathrm{QALY} / \text { time horizon }] \times[\text { number of users }]
\end{aligned}
$$

As explained in the original publication (1), QALY value in this context meant QALY threshold and for cost/QALY, the ICER or ICUR derived from published CEA was used. First, the ICER/ICUR was subtracted from the QALY threshold mentioned above. Second, the result was multiplied with the additional QALYs gained or lost by the new drug divided by the time horizon to get the additional QALYs gained or lost in 1 year and last, the result was multiplied with the number of users.

Uncommonly, some new drugs do not only have better outcomes, i.e., more LYs or QALYs are gained, but are also cheaper than the alternative drugs. In this situation, where the resulting ICER/ICUR is negative it is called dominant and usually, no ICER/ICUR is reported. But for the purpose of this study, it was necessary to express all results as ICERs/ICURs, even if they were negative. Hence, in these cases where the new drug had better outcomes and was also cheaper than the standard treatment, a negative ICER/ICUR was presented. This influenced the equation in such a way, that in these cases the first part of the equation turned into QALY $_{\text {value }}+$ cost/QALY, which led to a higher potential welfare gain.

\section{ADJUSTMENT OF THE DATA TO THE SWISS SITUATION IN 2010}

Including only cost-effectiveness studies performed from a Swiss perspective would have been preferred. Due to the fact that only few cost-effectiveness studies have been conducted in a Swiss setting, most cost-effectiveness studies included in our analysis were studies from foreign countries. Accordingly, there was a need to adjust the data to Switzerland before running the equation. The ICERs/ICURs were first adjusted to the year 2010 of the original country by using the deflator of GDP $(20-25,30)$. Then, PPPs were used to convert the foreign ICER/ICUR results to Swiss francs (27).

\section{UNIVARIABLE SENSITIVITY ANALYSIS}

A univariate sensitivity analysis was conducted. Costs/QALY, i.e., the ICER or ICUR adjusted to Switzerland, the QALY effect itself, and the time horizon were varied between 80 and $120 \%$ of the original values $( \pm 20 \%)$. The formula shows that varying the QALY effect and the number of users to the same extent would lead to the same welfare impact. Therefore, the number of users was varied between 50 and $150 \%$ of the original values $( \pm 50 \%)$. In addition, the calculation was performed using a QALY threshold of CHF 50,000 reflecting also lower QALY thresholds such as in the US and the UK and using a very high QALY threshold of CHF 150,000 .

\section{RESULTS}

\section{LITERATURE SEARCH}

Our search identified 175 citations found in PubMed, CEA, and in CRD. Titles and abstracts of all references were screened to identify cost-effectiveness and cost-utility analyses. Full-texts were considered for the final inclusion of 31 studies (Table 1), of which 29 were conducted in foreign settings and only two studies that also met the inclusion criteria were conducted in a Swiss setting. There was no need for adjustment of the data of these two studies (28, 29). Articles were mainly excluded because they did not report an ICER/ICUR or they did not fulfill other pre-defined inclusion criteria. 
Table 1 | Drugs included in the welfare basket.

\begin{tabular}{|c|c|c|c|}
\hline Number & Drug & Brand & Company \\
\hline 1 & $\begin{array}{l}\text { Bosentan } \\
\text { monohydrate (34) }\end{array}$ & Tracleer® & Actelion \\
\hline 2 & Peginterferon alfa 2a (35) & Pegasys $®$ & Roche \\
\hline 3 & Conjugated vaccine (36) & Prevenar® & Wyeth \\
\hline 4 & Ezetimibe (37) & Ezetrol ( & $\begin{array}{l}\text { Merck Sharp \& } \\
\text { Dohme }\end{array}$ \\
\hline 5 & Sirolimus (38) & Rapamune® & Wyeth \\
\hline 6 & Interferon beta-1a (39) & Avonex® & Biogen \\
\hline 7 & Ibandronate (40) & Bonviva $®$ & Roche \\
\hline 8 & Rizatriptan (41) & Maxalt@ & $\begin{array}{l}\text { Merck Sharp \& } \\
\text { Dohme }\end{array}$ \\
\hline 9 & Linezolid (42) & Zyvoxid® & Pfizer \\
\hline 10 & Rivastigmine (43) & Exelon® & Novartis \\
\hline 11 & Rosiglitazone (44) & Avandia® & GlaxoSmithKline \\
\hline 12 & Oseltamivir (45) & Tamiflu® & Roche \\
\hline 13 & Clopidogrel (46) & Plavix $®$ & Bristol-Myers Squibl \\
\hline 14 & Memantine (47) & Ebixa® & H. Lundbeck \\
\hline 15 & Risperidone (48) & Risperdal@ & Janssen-Cilag \\
\hline 16 & Atomoxetine (49) & Strattera ${ }^{\circledR}$ & Eli Lilly \\
\hline 17 & Atorvastatin (50) & Lipitor® & Pfizer \\
\hline 18 & Orlistat (51) & Xenical® & Roche \\
\hline 19 & Natalizumab (52) & Tysabri® & Elan Pharma \\
\hline 20 & Oxaliplatin (53) & Eloxatin $®$ & Sanofi-Aventis \\
\hline 21 & Rosuvastatin (54) & Crestor ${ }^{\circledR}$ & AstraZeneca \\
\hline 22 & Trastuzumab (55) & Herceptin $®$ & Roche \\
\hline 23 & Cinacalcet (56) & Mimpara® & Amgen Europe \\
\hline 24 & Sitagliptin (57) & Januvia ${ }^{\circledR}$ & $\begin{array}{l}\text { Merck Sharp \& } \\
\text { Dohme }\end{array}$ \\
\hline 25 & Rimonabant (58) & Acomplia® & Sanofi-Aventis \\
\hline 26 & Pimecrolimus (59) & Elide ${ }^{\circledR}$ & Novartis \\
\hline 27 & $\begin{array}{l}\text { Human papillomavirus } \\
\text { vaccine (28) }\end{array}$ & Gardasil $\circledast$ & $\begin{array}{l}\text { Merck Sharp \& } \\
\text { Dohme }\end{array}$ \\
\hline 28 & Fulvestrant (60) & Faslodex® & AstraZeneca \\
\hline 29 & Erlotinib (61) & Tarceva® & Roche \\
\hline 30 & Eplerenone (62) & Inspra® & Pfizer \\
\hline 31 & Raltegravir (29) & Isentress $®$ & $\begin{array}{l}\text { Merck Sharp \& } \\
\text { Dohme }\end{array}$ \\
\hline
\end{tabular}

\section{WELFARE IMPACT (BASE-CASE)}

For every drug, the welfare impact was calculated separately according to the formula described before. Generally, the results of the individual drugs differed broadly (Table 2). There were some drugs which did not generate much potential welfare gain over 1 year compared to the standard treatment, e.g., peginterferon alfa 2a (CHF 658,144), risperidone (CHF 996,206), rimonabant $(7,759)$, HPV vaccine $(22,157)$, and others. Then, there were drugs where the evidence of potential welfare gains with the introduction of these drugs was much higher, e.g., bosentan monohydrate (CHF 10,717,090), clopidrogrel (CHF 257,359,200), pimecrolimus (CHF $54,412,070)$, etc. Nevertheless, each of the 31 reviewed drugs generated a positive result, meaning a clear welfare gain, except one of the drugs. The introduction of cinacalcet (mimpara) to the Swiss market resulted in a monetary loss compared to the standard treatment. To obtain the total welfare impact for the Swiss economy due to the introduction of innovative drugs to the Swiss market, all results were summed up, which led to a total potential welfare gain of CHF 781.39 million for the year 2010 (Table 2). This amounted to about $0.0014 \%$ of the GDP in Switzerland in 2010 (30).

\section{SENSITIVITY ANALYSIS}

All results of the univariate sensitivity analysis showed the robustness of the base-case findings, meaning that for every variation of the input parameters, there was a potential welfare gain. The most influential parameter was the QALY threshold followed by the number of users (Figure 3), which were both varied by $50 \%$. When using a QALY threshold of CHF 50,000, the potential welfare gain was only CHF 260.77 million, which was the lowest calculated. In the sensitivity analysis, the potential welfare gain ranged from CHF 260.77 million to CHF 1.30 billion (Figure 3).

\section{DISCUSSION}

To the best of our knowledge, this study is the first attempt to calculate the welfare impact of innovative drugs in a Swiss setting. Although the costs of the most innovative drugs often surpass the costs of previous or existing pharmaceuticals, prescribing newer drugs is still reasonable, at least in most cases due to more benefits. Our base-case results showed that introducing innovative drugs to the Swiss market led to potential welfare gains in 2010 accounting for approximately CHF 781.39 million, which accounts for $13 \%$ of total drug expenditure in 2010 in Switzerland (5). There was only one drug included in our study that led to additional costs per QALY gained compared to the standard treatment, i.e., which decreased the potential welfare gained for the Swiss economy. The sensitivity analysis showed that results were robust.

Some of the general limitations specific to the calculation approach used in this study have already been discussed by the original report published by Tsiachristas et al. (1). We are aware that the formula created by the authors has not been utilized widely; further validation is deemed necessary. Nevertheless, there do not seem any a priori reasons to assume that the derived model would not perform sufficiently adequate for our study question. Other limitations include inconsistencies in the economic evaluation, international differences in health care systems and health determinants, limited data availability and lack of agreement about the appropriate valuation of a QALY. Therefore, in the next section, we will focus on limitations specific to our study.

\section{LIMITATIONS OF THE STUDY}

The main limitation of this study was probably the lack of Swissspecific data and when interpreting the welfare impact results, it must be considered that in this study the obtained costeffectiveness data for Switzerland, i.e., the obtained ICERs/ICURs for our calculations were in almost all the cases adjusted from 
Table 2 | Input parameters used for the welfare impact calculations.

\begin{tabular}{|c|c|c|c|c|c|c|c|c|}
\hline Drug & $\begin{array}{l}\text { Cost/QALY } \\
\text { or LYG }\end{array}$ & $\begin{array}{l}\text { ICER for } \\
\text { CH } 2010\end{array}$ & QALY effect ${ }^{\mathrm{a}}$ & $\begin{array}{l}\text { Time } \\
\text { horizon } \\
\text { (years) }\end{array}$ & Year & Valuta & Perspective & $\begin{array}{l}\text { Welfare } \\
\text { impact } \\
\text { (CHF) }\end{array}$ \\
\hline $\begin{array}{l}\text { Peginterferon alfa 2a } \\
\text { (Pegasys } ®)\end{array}$ & 10,444/QALY & $17,337.2$ & $0.3 \mathrm{QALY}$ & 47.1 & 2005 & GBP & NHS & 658,144 \\
\hline Ezetimibe (Ezetro|®) & $27,475 / L Y G$ & $44,746.56$ & $0.134 \mathrm{LY}$ & 24.1 & 2006 & GBP & Health care payer & $6,234,995$ \\
\hline Sirolimus (Rapamune®) & $-27,047 / L Y G$ & $-33,372.4$ & $1.8 \mathrm{LY}$ & 20 & 2003 & GBP & NHS & $18,005,274$ \\
\hline $\begin{array}{l}\text { Interferon beta-1a } \\
\text { (Avonex®) }\end{array}$ & 44,789/MLY & $49,449.91$ & 1.21 MLY & 12 & 2002 & CAD & Societal & $1,778,900$ \\
\hline Linezolid (Zyvoxid@) & 29,945/QALY & $34,533.36$ & 6.73 QALY & 9 & 2001 & CAD & Third-party payer & $10,769,990$ \\
\hline Rivastigmine (Exelon®) & 7,249/QALY & $7,561.74$ & 0.0077 QALY & 0.46 & 2004 & CAD & Societal & $13,303,996$ \\
\hline $\begin{array}{l}\text { Rosiglitazone } \\
\text { (Avandia } 囚)\end{array}$ & $5,137 / \mathrm{QALY}$ & $9,147.21$ & 0.1464 QALY & 20 & 2000 & GBP & NHS & $3,486,152$ \\
\hline Oseltamivir (Tamiflu®) & $-6,182 /$ QALY & $-5,226.96$ & 0.0034 QALY & 1 & 2006 & USD & Societal & $3,630,309$ \\
\hline Clopidogrel (Plavix®) & $25,100 / \mathrm{QALY}$ & $28,618.51$ & 0.55 QALY & 14.2 & 2002 & USD & Societal & $257,359,176$ \\
\hline Memantine (Ebixa®) & $-6,613 / \mathrm{QALY}$ & $-5,322.69$ & 0.0276 QALY & 2 & 2005 & USD & Societal & $4,550,762$ \\
\hline $\begin{array}{l}\text { Risperidone } \\
\text { (Risperdal }(\text { ) }\end{array}$ & 39,890/QALY & $40,619.47$ & 0.0509 QALY & 5 & 2006 & USD & Health care payer (Brazil) & 996,206 \\
\hline Rosuvastatin (Crestor®) & 36,548/QALY & $49,426.78$ & 0.08 QALY & 23.5 & 2006 & EUR & Health care payer (Finland) & $15,291,792$ \\
\hline $\begin{array}{l}\text { Trastuzumab } \\
\text { (Herceptin®) }\end{array}$ & 35,975/QALY & $49,153.24$ & $0.262 \mathrm{QALY}$ & 25.4 & 2005 & EUR & Societal (Sweden) & $1,216,275$ \\
\hline Cinacalcet (Mimpara $\left.{ }^{\circledR}\right)$ & 61,890/QALY & $104,433.05$ & 0.34 QALY & 24.1 & 2004 & GBP & Health care payer & $-59,101$ \\
\hline Sitagliptin (Januvia®) & 11,547/QALY & $15,729.13$ & $0.095 \mathrm{QALY}$ & 14.2 & 2006 & EUR & Health care payer (UK) & $7,543,994$ \\
\hline $\begin{array}{l}\text { Rimonabant } \\
\text { (Acomplia®) }\end{array}$ & 71,973/QALY & $73,289.18$ & 0.0581 QALY & 5 & 2006 & USD & Third-party payer & 7,759 \\
\hline Pimecrolimus (Elidel®) & 35,000/QALY & $38,642.23$ & 0.03 QALY & 0.5 & 2002 & CAD & Societal & $54,412,070$ \\
\hline HPV vaccine (Gardasil囚) & $26,005 / \mathrm{QALY}$ & 26,885 & $0.020 \mathrm{OALY}$ & 70.55 & 2006 & $\mathrm{CHF}$ & Health care payer & 22,157 \\
\hline Fulvestrant (Faslodex®) & $-33,571 /$ QALY & $-40,140.15$ & $0.021 \mathrm{QALY}$ & 10 & 2007 & EUR & Health care payer (Germany) & 316,366 \\
\hline Erlotinib (Tarceva®) & $-212,700 / \mathrm{QALY}$ & $-184,240.96$ & $0.01 \mathrm{QALY}$ & 2 & 2007 & USD & Health care payer & 956,471 \\
\hline Eplerenone (Inspra®) & 20,579/QALY & $23,732.24$ & 0.0676 QALY & 12.8 & 2001 & USD & Health care payer & 511,542 \\
\hline Raltegravir (Isentress $®$ ) & 45,687/QALY & 46,906 & 3.73 QALY & 50 & 2007 & $\mathrm{CHF}$ & Health care payer & $\begin{array}{l}4,440,071 \\
781,388,456\end{array}$ \\
\hline
\end{tabular}

QALY, quality-adjusted life year; ICER, incremental cost-effectiveness ratio; LYG, life year gained; NHS, National Health Service; MLY, monosymptomatic life year. For reasons of confidentiality, the number of actual users is not declared.

${ }^{a} Q A L Y$ effect means difference in quality-adjusted life years between treatment and comparator strategy. 


\section{Base-case potential welfare gain CHF 781 million}

QALY threshold (CHF 50'000 - 150'000)

number of users $(+/-50 \%)$

time horizon (+/- 20\%)

$\triangle Q A L Y$ effect $(+/-20 \%)$

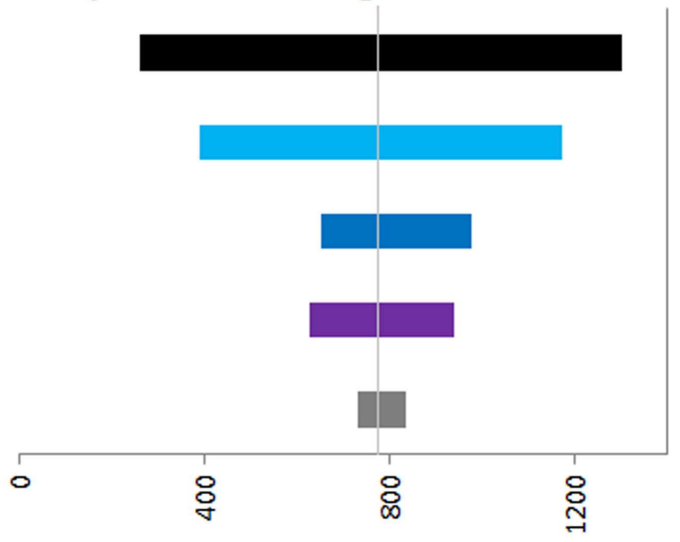

ICER $(+/-20 \%)$

Potential welfare gain in million $\mathrm{CHF}$

FIGURE 3 | Tornado diagram showing the results of the sensitivity analysis

foreign cost-effectiveness data. As the costs of drugs, the life expectancy, the national economy, and other factors affecting the ICER/ICUR estimate differ between countries, the ICERs/ICURs from another country might not be applicable to Switzerland without further adjustments in addition to GDP and PPP conversions. For example, the comparative standard treatment used in the country, the cost-effectiveness analysis was performed for might differ from the standard treatment used in Switzerland. In an economic analysis, the new treatment should always be compared with the most relevant comparator in that setting or country. Therefore, the ICER/ICUR of a new treatment in a foreign country compared to the county-specific relevant standard treatment might not be exactly transferable to the Swiss setting. Because a QALY is calculated by multiplying the utility weight of a given state with the life years being in this state (31) and these utilities are not the same among countries, the QALYs gained or lost with the new drug compared to the standard treatment might differ among countries. For these reasons, it would have been desirable to use only Swiss data for our calculations to get a more reliable estimate of the welfare impact of innovative drugs in Switzerland.

Another limitation of the study and its findings resulted from the fact that many included studies were from a third-party payer perspective and not from a societal perspective. Studies from a third-party payer perspective only include direct costs, such as hospitalization costs, drug costs, physician costs, etc. To assess the welfare impact of innovative drugs, also indirect costs, e.g., productivity losses, work absences, informal care by family members, etc., should be considered as these can have a substantial effect on the resulting ICER/ICUR of a new drug compared to standard treatment. Because the majority of the included costeffectiveness studies were from a third-party payer perspective and those studies from a societal perspective did not always met the other pre-defined inclusion criteria, we decided to also include studies from a third-party payer perspective. Otherwise, our basket of innovative drugs available to calculate the welfare impact in Switzerland in 2010 would have been much smaller and might not have been representative of innovative drugs in Switzerland. Bearing in mind that we only included 31 drugs in our calculations and in Switzerland approximately 700 new drugs were registered since 2000 onward (32), the inclusion of studies was very restrictive and the potential welfare gain could even be higher.

A further limitation is the number of users derived for our calculations. Very often there was not much information available about the potential users and therefore, we had to use the number of actual users in the year 2010 as an approximate estimate for the number of potential users (except for Conjugated vaccine, ibandronate, atorvastatin, and memantine), which is not always consistent. Furthermore, it was not possible to obtain the number of actual users directly from the manufacturers for every drug. For risperidone and cinacalcet, an estimate had to be made based on data from the number of sold packages in Switzerland (information was provided from the manufactures who had this number from IMS Health sales figures) and the standard dose for the specific drug (19). All other numbers of actual users were provided by the Helsana Group, the largest health insurer in Switzerland. With 1.8 million Swiss people insured (33), we think that Helsana is representative enough to estimate the actual users in Switzerland. As actual users might differ from potential users and the welfare impact calculations depend on the number of users, we were aware that the result could differ substantially.

It must be mentioned that not all of the cost-effectiveness studies measured the clinical effects expressed in QALYs, which was the preferred outcome measure. Instead, for five drugs (bosentan monohydrate, conjugated vaccine, ezetimibe, sirolimus, and ibandronate) the effect was measured in LYG which does not take into account the quality of life during the additional LYG by the new drug. The equivalent QALY estimate could be much lower, e.g., the patient gained one life year by the new treatment but the quality of life was as bad as 0.2 and therefore, the new drug would only have a benefit of 0.2 QALYs gained instead of one LYG meaning that the calculated welfare impact of these five drugs might be lower when calculated by using QALYs. The same applied for the welfare 
impact calculations of interferon beta-1a. The authors of this study used monosymptomatic life years (MLY) as the measure of effect.

Some drugs included in our study (bosentan monohydrate, peginterferon $2 \mathrm{a}$, ibandronate, risperidone, oxaliplatin, trastuzumab, cinacalcet, and erlotinib) are used for more than one indication. In all cases, the cost-effectiveness study was conducted for one indication only. The information about volume of users we got from the manufacturers of the drug or Helsana, or we calculated based on the number of sold packages made no difference between the diverse indications. But it is very likely that the QALY gain of the drug is not the same for every indication. For these particular drugs, we might have overestimated the welfare impact by using the total number of volume users independent from indication and the QALY effect of the drug measured for only one indication.

Nevertheless, our calculations were conservative and included only a small portion of the total number of innovative drugs launched 2000 onward in Switzerland. The potential welfare gain generated by the introduction of new drugs in Switzerland in 2010 was substantial and the sensitivity analysis showed that using a lower QALY threshold of CHF 50,000 also led to a potential welfare gain in 2010. Together with the fact that the prices of many new drugs in Switzerland have decreased, the total potential welfare gain might be even greater. As one drug (Mimpara) showed negative welfare effects, we cannot generally conclude that there is a positive welfare effect of new drugs compared to standard treatment. But this finding should effect that health decision makers do not only discuss the price of a new pharmaceutical but also its benefit, ideally expressed in QALYs. For this purpose, there is an urgent need for performing CEA of novel pharmaceuticals, if possible prior to the introduction to the market.

\section{ACKNOWLEDGMENTS}

We want to thank Oliver Reich and Pius Gyger from the Helsana Insurance Group for providing us with the numbers of actual users of the medicines evaluated in this study.

\section{REFERENCES}

1. Tsiachristas A, Goudriaan R, Groot W. The Welfare Effects of Innovative Pharmaceuticals: A Pilot Study for the Netherlands. The Hague: Aarts De Jong Wilms Goudriaan Public Economics by APE and Maastricht University (2008).

2. Squires DA. Explaining high health care spending in the United States: an international comparison of supply, utilization, prices, and quality. Commonw Fund (2012) 10:1-14.

3. Bundesamt für Statistik (BFS). Thema Gesundheit-Kosten, Finanzierung: Daten, Indikatoren. Kosten des Gesundheitswesens nach Leistungen 1995-2010. BFS (2012). Available from http://www.bfs.admin.ch/bfs/portal/de/index/themen/ 14/05/blank/key/leistungserbringer.html

4. OECD. Health - Health Policies and Data: OECD Health Data 2012 (OECD.Stat). Health Expenditure and Financing - Total Health Expenditure by Function. [cited 2012 Sep 26]. Available from: http://stats.oecd.org/index.aspx?DataSetCode= HEALTH_STAT

5. Interpharma. Fakten und Statistiken - Pharma-Markt Schweiz: Nutzen und Kosten von Medikamenten. Aufteilung der Gesundheitskosten nach Leistungen. [cited 2012 Sep 10]. Available from: http://www.interpharma.ch/de/faktenund-statistiken/pharma-markt-schweiz/Aufteilung_der_Gesundheitskosten_ nach_Leistungen_2009.asp?ShowBackButton=1

6. Telser H, Fischer B, Leukert K, Vaterlaus S. Gesundheitsausgaben und Krankheitskosten. Interpharma/Polynomics (2011).

7. Lichtenberg FR. Despite steep costs, payments for new cancer drugs make economic sense. Nat Med (2011) 17(3):244. doi:10.1038/nm0311-244
8. Martin S, Rice N, Smith PC. Does health care spending improve health outcomes? Evidence from English programme budgeting data. J Health Econ (2008) 27:826-42. doi:10.1016/j.jhealeco.2007.12.002

9. Vavken P, Pagenstert G, Grimm C, Dorotka R. Does increased health care spending afford better health care outcomes? Swiss Med Wkly (2012) 142:w13589. doi:10.4414/smw.2012.13589

10. Lichtenberg FR. Benefits and costs of newer drugs: an update. MDE Manage Decis Econ (2007) 28(4-5):485-90. doi:10.3310/hta14360

11. Luce BR, Mauskopf J, Sloan FA, Ostermann J, Paramore LC. The return on investment in health care: from 1980 to 2000. Value Health (2006) 9(3):146-56. doi:10.1111/j.1524-4733.2006.00095.x

12. Civan A, Köksal B. The effect of newer drugs on health spending: do they really increase the costs? Health Econ (2010) 19:581-95. doi:10.1002/hec.1494

13. Light DW, Lexchin JR. Pharmaceutical research and development: what do we get for all that money? BMJ (2012) 344:e4348. doi:10.1136/bmj.e4348

14. Mijuk G, Jacquemart C. Wieviel Darf Ein Leben Kosten? NZZ am Sonntag. Swiss Newspaper. (2011)

15. Bundesgerichtsentscheid 9C_334/2010 - Regeste und Auszüge des Entscheids vom 23. Bioethica Forum (2011) 4(3):88-91.

16. Meltzer M. Introduction to health economics for physicians. Lancet (2001) 358:993-8. doi:10.1016/S0140-6736(01)06107-4

17. WHO. Cost-Effectiveness Thresholds. [cited 2012 Sep 14]. Available from: http: //www.who.int/choice/costs/CER_thresholds/en/index.html

18. NICE. Measuring Effectiveness and Cost Effectiveness: The QALY. [cited 2012 Sep 14]. Available from: http://www.nice.org.uk/newsroom/features/ measuringeffectivenessandcosteffectivenesstheqaly.jsp

19. Arzneimittel-Kompendium der Schweiz. [cited 2011 Feb 15]. Available from: http://www.kompendium.ch/home/de

20. Inflation Data. Inflation - Inflation Calculator: Price Inflation Calculator. [cited $2011 \mathrm{Feb} 15]$. Available from: http://www.inflationdata.com/inflation/Inflation Calculators/Inflation_Rate_Calculator.asp

21. Global Rates. Wirtschaftsstatistiken - Inflation: Verbraucherpreisindex VPI. VPI Grossbritannien. [cited 2011 Feb 15]. Available from: http://de.global-rates.com/ wirtschaftsstatistiken/inflation/verbraucherpreisen/vpi/grossbritannien.aspx]

22. Global Rates. Wirtschaftsstatistiken - Inflation: Verbraucherpreisindex VPI. VPI Finland. [cited 2011 Feb 15]. Available from: http://de.global-rates.com/ wirtschaftsstatistiken/inflation/verbraucherpreisen/vpi/finnland.aspx

23. Inflation.eu. Sweden - Historic Inflation Sweden: Extensive Info. [cited 2011 Feb 15]. Available from: http://www.inflation.eu/inflation-rates/sweden/ historic-inflation/cpi-inflation-sweden.aspx

24. Reserve Bank of Australia. Statistics - Inflation Calculator. [cited 2011 Feb 15]. Available from: http://www.rba.gov.au/calculator/

25. Bank of Canada. Rates and Statistics - Related Information: Inflation Calculator. [cited 2011 Feb 15]. Available from: http://www.bankofcanada.ca/en/rates/ inflation_calc.html

30. Bundesamt für Statistik. Themen - Preise: Landesindex der Konsumentenpreise. LIK-Teuerungsrechner. [cited $2011 \mathrm{Feb} 15$ ]. Available from: http://www. portal-stat.admin.ch/lik_rechner/d/lik_rechner.htm

27. Finanzen.net. Börse-Devisen: Währungsrechner. [cited 2011 Feb 15]. Available from: http://www.portal-stat.admin.ch/lik_rechner/d/lik_rechner.htm

28. Szucs TD, Largeron N, Dedes KJ, Rafia R, Bénard S. Cost-effectiveness analysis of adding a quadrivalent HPV vaccine to the cervical cancer screening program in Switzerland. Curr Med Res Opin (2008) 24(5):1473-83. doi:10.1185/ 030079908 X297826

29. Elbasha EE, Szucs T, Chaudhary MA, Kumar RN, Roediger A, Cook JR, et al. Cost-effectiveness of raltegravir in antiretroviral treatment-experienced HIV-1-infected patients in Switzerland. HIV Clin Trials (2009) 10(4):233-53. doi:10.1310/hct1004-233

30. Bundesamt für Statistik (BFS). Thema Volkswirtschaft - Bruttoinlandsprodukt: Daten, Indikatoren. [cited 2012 Oct 17]. Available from: http://www.bfs.admin. ch/bfs/portal/de/index/themen/04/02/01/key/bip_gemaess_produktionsansatz. html

31. Dolan P. Thinking about it: thoughts about health and valuing QALYs. Health Econ (2011) 20:1407-16. doi:10.1002/hec.1679

32. Interpharma. Fakten und Statistiken - Pharma-Markt Schweiz: Zulassung, Preisbildung und Rückerstattung von Medikamenten. Anzahl zugelassener Medikamente in der Schweiz. [cited 2012 Sep 30]. Available from: http://www. interpharma.ch/de/fakten-und-statistiken/pharma-markt-schweiz/Anzahl_ zugelassener_Medikamente_in_der_Schweiz.asp?ShowBackButton=1 
33. Helsana. Über uns: Zahlen and Fakten - Kennzahlen. Versicherte. [cited 2012 Sep 28]. Available from: http://www.helsana.ch/de/ueber_uns/zahlen_und_fakten/ kennzahlen/

34. Wlodarczyk JH, Cleland LG, Keogh AM. Public funding of bosentan for the treatment of pulmonary artery hypertension in Australia: cost effectiveness and risk sharing. Pharmacoeconomics (2006) 24(9):903-15. doi:10.2165/00019053200624090-00007

35. Veenstra DL, Sullivan SD, Dusheiko GM, Jacobs M, Aledort JE, Lewis G, et al. Cost-effectiveness of peginterferon alpha-2a compared with lamivudine treatment in patients with $\mathrm{HBe}$-antigen-positive chronic hepatitis B in the United Kingdom. Eur J Gastoenterol Hepatol (2007) 19(8):631-8. doi:10.1097/MEG. 0b013e3281108079

36. McIntosh ED, Conway P, Willingham J, Lloyd A. The cost-burden of paediatric pneumococcal disease in the UK and the potential cost-effectiveness of prevention using 7-valent pneumococcal conjugate vaccine. Vaccine (2003) 21(1920):2564-72. doi:10.1016/S0264-410X(03)00031-8

37. Ara R, Pandor A, Tumur I, Paisley S, Duenas A, Williams R, et al. Estimating the health benefits and costs associated with ezetimibe coadministered with statin therapy compared with higher dose statin monotherapy in patients with established cardiovascular disease: results of a Markov model for UK costs using data registries. Clin Ther (2008) 30(8):1508-23. doi:10.1016/j.clinthera.2008.08.002

38. McEwan P, Dixon S, Baboolal K, Conway P, Currie CJ. Evaluation of the cost effectiveness of sirolimus versus tacrolimus for immunosuppression following renal transplantation in the UK. Pharmacoeconomics (2006) 24(1):67-79. doi:10.2165/00019053-200624010-00006

39. Iskedjian M, Walker JH, Gray T, Vicente C, Einarson TR, Gehshan A. Economic evaluation of Avonex (interferon beta-Ia) in patients following a single demyelinating event. Mult Scler (2005) 11(5):542-51. doi:10.1191/ $1352458505 \mathrm{~ms} 1211$ oa

40. De Cock E, Hutton J, Canney P, Body JJ, Barrett-Lee P, Neary MP, et al. Cost-effectiveness of oral ibandronate compared with intravenous (i.v.) zoledronic acid or i.v. generic pamidronate in breast cancer patients with metastatic bone disease undergoing i.v. chemotherapy. Support Care Cancer (2005) 13(12):975-86. doi:10.1007/s00520-005-0828-1

41. Thompson M, Gawel M, Desjardins B, Ferko N, Grima D. An economic evaluation of rizatriptan in the treatment of migraine. Pharmacoeconomics (2005) 23(8):837-50. doi:10.2165/00019053-200523080-00008

42. Plosker GL, Figgitt DP. Linezolid: a pharmacoeconomic review of its use in serious Gram-positive infections. Pharmacoeconomics (2005) 23(9):945-64. doi:10.2165/00019053-200523090-00006

43. Willan AR, Goeree R, Pullenayegum EM, McBurney C, Blackhouse G. Economic evaluation of rivastigmine in patients with Parkinson's disease dementia. Pharmacoeconomics (2006) 24(1):93-106. doi:10.2165/00019053-200624010-00008

44. Czoski-Murray C, Warren E, Chilcott J, Beverley C, Psyllaki MA, Cowan J. Clinical effectiveness and cost-effectiveness of pioglitazone and rosiglitazone in the treatment of type 2 diabetes: a systematic review and economic evaluation. Health Technol Assess (2004) 8(13):iii, ix-x, 1-91. doi:10.3310/hta8130

45. Talbird SE, Brogan AJ, Winiarski AP, Sander B. Cost-effectiveness of treating influenza like illness with oseltamivir in the United States. Am J Health Syst Pharm (2009) 66(5):469-80. doi:10.2146/ajhp080296

46. Schleinitz MD, Weiss JP, Owens DK. Clopidogrel versus aspirin for secondary prophylaxis of vascular events: a cost-effectiveness analysis. Am J Med (2004) 116(12):797-806. doi:10.1016/j.amjmed.2004.01.014

47. Weycker D, Taneja C, Edelsberg J, Erder MH, Schmitt FA, Setyawan J, et al. Costeffectiveness of memantine in moderate-to-severe Alzheimer's disease patients receiving donepezil. Curr Med Res Opin (2007) 23(5):1187-97. doi:10.1185/ $030079907 X 188071$

48. Lindner LM, Marasciulo AC, Farias MR, Grohs GE. Economic evaluation of antipsychotic drugs for schizophrenia treatment within the Brazilian Healthcare System. Rev Saude Publica (2009) 43(Suppl 1):62-9.

49. Prasad S, Arellano J, Steer C, Libretto SE. Assessing the value of atomoxetine in treating children and adolescents with ADHD in the UK. Int J Clin Pract (2009) 63(7):1031-40. doi:10.1111/j.1742-1241.2009.02090.x

50. Lindgren P, Graff J, Olsson AG, Pedersen TJ, Jönsson B, IDEAL Trial Investigators. Cost-effectiveness of high-dose atorvastatin compared with regular dose simvastatin. Eur Heart J (2007) 28(12):1448-53. doi:10.1093/ eurheartj/ehm020

51. Hertzman P. The cost effectiveness of orlistat in a 1-year weight-management programme for treating overweight and obese patients in Sweden: a treatment responder approach. Pharmacoeconomics (2005) 23(10):1007-20. doi:10.2165/ 00019053-200523100-00004

52. Kobelt G, Berg J, Lindgren P, Jonsson B, Stawiarz L, Hillert J. Modeling the cost-effectiveness of a new treatment for MS (natalizumab) compared with current standard practice in Sweden. Mult Scler (2008) 14(5):679-90. doi:10.1177/1352458507086667

53. Aballéa S, Boler A, Craig A, Wasan H. An economic evaluation of oxaliplatin for the adjuvant treatment of colon cancer in the United Kingdom (UK). Eur J Cancer (2007) 43(11):1687-93. doi:10.1016/j.ejca.2007.05.001

54. Peura P, Martikainen J, Soini E, Hallinen T, Niskanen L. Cost-effectiveness of statins in the prevention of coronary heart disease events in middleaged Finnish men. Curr Med Res Opin (2008) 24(6):1823-32. doi:10.1185/ 03007990802144705

55. Lidgren M, Jönsson B, Rehnberg C, Willking N, Bergh J. Cost-effectiveness of HER2 testing and 1-year adjuvant trastuzumab therapy for early breast cancer. Ann Oncol (2008) 19(3):487-95. doi:10.1093/annonc/mdm488

56. Garside R, Pitt M, Anderson R, Mealing S, D'Souza R, Stein K. The cost-utility of cinacalcet in addition to standard care compared to standard care alone for secondary hyperparathyroidism in end-stage renal disease: a UK perspective. Nephrol Dial Transplant (2007) 22(5):1428-36. doi:10.1093/ndt/gfl774

57. Schwarz B, Gouveia M, Chen J, Nocea G, Jameson K, Cook J, et al. Costeffectiveness of sitagliptin-based treatment regimens in European patients with type 2 diabetes and haemoglobin Alc above target on metformin monotherapy. Diabetes Obes Metab (2008) 10(Suppl 1):43-55. doi:10.1111/j.1463-1326.2008. 00886.x

58. Hampp C, Hartzema AG, Kauf TL. Cost-utility analysis of rimonabant in the treatment of obesity. Value Health (2008) 11(3):389-99. doi:10.1111/j.15244733.2007.00281.x

59. Coyle D, Barbeau M. Cost effectiveness of Elidel in the management of patients with atopic dermatitis in Canada. J Cutan Med Surg (2004) 8(6):405-10. doi:10.1007/s10227-004-0111-y

60. Lux MP, Hartmann M, Jackisch C, Raab G, Schneeweiss A, Possinger K, et al. Cost-utility analysis for advanced breast cancer therapy in Germany: results of the fulvestrant sequencing model. Breast Cancer Res Treat (2009) 117(2):305-17. doi:10.1007/s10549-008-0294-9

61. Carlson JJ, Reyes C, Oestreicher N, Lubeck D, Ramsey SD, Veenstra DL. Comparative clinical and economic outcomes of treatments for refractory non-small cel lung cancer (NSCLC). Lung Cancer (2008) 61(3):405-15. doi:10.1016/j.lungcan. 2007.12.023

62. Weintraub WS, Zhang Z, Mahoney EM, Kolm P, Spertus JA, Caro J, et al. Costeffectiveness of eplerenone compared with placebo in patients with myocardia infarction complicated by left ventricular dysfunction and heart failure. Circulation (2005) 111(9):1106-13. doi:10.1161/01.CIR.0000157146.86758.BC

Conflict of Interest Statement: The authors declare that the research was conducted in the absence of any commercial or financial relationships that could be construed as a potential conflict of interest.

Received: 07 February 2014; accepted: 05 May 2014; published online: 20 May 2014. Citation: Pavic M, Pfeil AM and Szucs TD (2014) Estimating the potential annual welfare impact of innovative drugs in use in Switzerland. Front. Public Health 2:48. doi: $10.3389 / f p u b h .2014 .00048$

This article was submitted to Epidemiology, a section of the journal Frontiers in Public Health.

Copyright (c) 2014 Pavic, Pfeil and Szucs. This is an open-access article distributed under the terms of the Creative Commons Attribution License (CC BY). The use, distribution or reproduction in other forums is permitted, provided the original author(s) or licensor are credited and that the original publication in this journal is cited, in accordance with accepted academic practice. No use, distribution or reproduction is permitted which does not comply with these terms. 